\title{
La actual política exterior norteamericana y su proyección en América Latina
}

\section{INTRODUCCIóN}

Para comprender las relaciones entre Estados Unidos y América Latina es preciso estudiarlas dentro de un contexto mundial. El solo marco del sistema interamericano sería insuficiente para su análisis ya que, por su calidad de superpotencia, EE. UU. es un actor mundial por excelencia y América Latina, en las últimas décadas, se ha convertido en un campo de interacciones políticas, económicas, sociales y culturales con el resto del mundo.

Por esta razón nos referiremos, primero, a algunos rasgos del mundo multipolar para pasar luego a situar dentro de dicho contexto el tema de nuestro estudio.

\section{La crisis de la hegemonía norteamericana y el mundo multipolar.}

Política y económicamente el planeta suele dividirse en tres mundos; en ellos se han producido profundos cambios. En el primer mundo "el cambio más fundamental de la situación internacional que emergió en la década del 70 fue el fin de la superioridad norteamericana tanto militar como económicamente" (Joffe, 81). Por su magnitud e importancia este cambio tuvo repercusiones en todo el sistema internacional: en la Alianza Atlántica, donde Europa y Japón percibieron el declinar del poder de EE. UU. y comenzaron a ajustar sus políticas frente a su aliado en un sentido de mayor independencia; en la uRss, el rival por excelencia de Washington, en la lucha por el predominio mundial y en el Tercer Mundo ( $y$ en América Latina como parte de él), que se percató que era posible desafiar el poder norteamericano, actitud simbolizada por el embargo petrolero del 73 y el episodio de los rehenes norteamericanos de Irán.

Con respecto al segundo mundo, en la izquierda mundial, incluidas las corrientes marxistas, se percibe la decadencia de Moscú como centro ideológico del marxismo-leninismo. Las críticas ideo- 
lógicas a Moscú tienen ahora un amplio espectro que va desde el extremo de la visión 'China (que condena a la uRss como una superpotencia imperialista, capitalista y fascista gobernada por una "clique" militar), abarca a los disidentes del bloque soviético, los eurocomunistas, los yugoslavos y una multitud de tendencias que afirman los caminos nacionales al socialismo aún en Europa Oriental. Polonia emerge como el símbolo de la crisis del modelo soviético. Erosionados crecientemente su liderazgo y prestigio ideológico, la URSs es percibida cada vez más como una superpotencia que lucha por el predominio mundial al igual que los EE. UU. Según algunos, emerge una nueva actitud antisoviética en los movimientos revolucionarios de liberación nacional, no sólo en la obvia instancia crítica de la revolución antimarxista de Irán, sino en la convicción de los líderes del Tercer Mundo, en todas, partes que el militarismo e imperialismo soviéticos constituyen amenazas para sus aspiraciones de independencia nacional y autodeterminación (Falk, 80). La percepción de la declinación imperial de la URss se apoya igualmente en múltiples factores domésticos cuyo análisis excede los límites de este estudio (G. Lagos, 8I).

En el Tercer Mundo se han reforzado las corrientes nacionalistas de distintos signos y ha emergido un consenso antiimperialista que coincide con una percepción, por parte del Sur, de que tanto los EE. UU. como la uRSS son dos imperios que, por distintas razones, se encuentran en declinación y que buscan la militarización de los conflictos para tratar de resistir o retardar la declinación de su hegemonía, ya que el imperativo es ejercer control cualquiera que sean los medios.

El Tercer Mundo ha empezado a buscar nuevos caminos de expresión a través de los cuales pueda romper sus vínculos de dependencia. La política de la OPEP, la alianza OPEP-Tercer Mundo para el Nuevo Orden Económico Internacional y el Diálogo Norte-Sur son indicadores claves de esta tendencia.

Al mismo tiempo se han producido cambios significativos en la estructura de la economía mundial. Al analizar las relaciones económicas de América Latina en un marco global de economía política con especial énfasis en las vinculaciones con el triángulo capitalista transnacional (formado por los polos norteamericano, europeo occidental y japonés) se destacan algunos aspectos fundamentales de la presente división internacional del trabajo: I) ha surgido la dependencia estratégica de los centros capitalistas con $r$ pecto a los países del Tercer Mundo, productores de ciertas materias primas; 2) la vieja división capitalista internacional del trabajo en que los países subdesarollados se incorporaban como simples productores de minerales o productos agricolas, se ha transformado, por el surgimiento de ciertos países como Brasil, México, Argentina, Venezuela, Corea del Sur y otros que se han convertido en zonas 
productoras y exportadoras de manufacturas, pasando a constituir una especie de semiperiferia distinta de la tradicional formada por el resto de las naciones que continúan exhibiendo características, problemas y necesidades típicas de sociedades subdesarrolladas; 3) esta industrialización de la semiperiferia se debe, entre otras causas, a la agudización de la dependencia estratégica de los centros que obliga a sus corporaciones transnacionales a transferir una parte o la totalidad del proceso de producción a zonas ventajosas como Brasil, por ejemplo, que cuentan con abundantes recursos naturales, mano de obra barata y amplios mercados y desde donde pueden competir eficientemente para cumplir sus propias finalidades; 4) la aparición de estos nuevos países en pleno proceso de industrialización ha significado el surgimiento de nuevos competidores por materias primas escasas, lo que ha agravado el problema de la dependencia estratégica y la rivalidad entre los centros, lo cual ha șubrayado la importancia económica de América Latina para el continuo progreso de EE. UU., Europa Occidental y Japón, como región rica en recursos minerales claves, mano de obra barata y mercados; 5) el desarrollo de relaciones competitivas entre los tres polos capitalistas con respecto a América Latina ha significado (pasada ya la etapa de casi exclusivo predominio económico norteamericano), que Europa Occidental y Japón han llegado progresivamente a tener niveles de participación en las relaciones económicas con América Latina, que ha mejorado considerablemente su posición relativa frente a EE. UU.; no obstante, las relaciones de la región con EE. UU. continúan siendo cruciales para el sector externo de la mayor parte de las economías latinoamericanas. Sin perjuicio de lo anterior, es necesario tener presente que el sistema capitalista se ha transnacionalizado efectivamente, lo que complica las distinciones nacionales en este campo; así, por ejemplo, el aumento del comercio latinoamericano con Europa Occidental necesariamente involucra a las subsidiarias europeas de empresas transnacionales norteamericanas como también en el financiamiento de los países latinoamericanos a través del mercado de eurodólares se encuentran envueltas las principales instituciones bancarias de EE. UU. Por último, es preciso recordar que dentro del capitalismo transnacional trilateral se da un considerable grado de coordinación entre las potencias industriales que lo constituyen; este hecho, junto a la alianza política existente entre los tres polos, señala los límites a la competencia entre EE. UU., Europa Occidental y Japón en sus relaciones con cualquier región del mundo, y por tanto, con América Latina. (G. Lagos, 79).

Las complejidades del mundo multipolar, algunos de cuyos rasgos hemos bosquejado, apuntan a un hecho central: entre el mundo de postguerra en el cual se dio la guerra fría y el actual, existen profundas diferencias. Después de la II Guerra Mundial los EE. UU. 
emergieron con un poder económico, financiero y militar incontrarrestable frente al resto del mundo. En el sistema internacional de nuestros días existen múltiples polos de poder mundial. Esta multipolaridad implica diversidad de intereses y de definiciones de política entre EE. UU., Europa Occidental, Japón, la URSs, el Tercer Mundo, los nuevos países industrializados, las corporaciones transnacionales, etc., que no pueden ser reducidos ni a la lógica maniquea ni a la estructura de poder dual propia de la guerra fría (G. Lagos, 81). La detente parecía corresponder a esta diversidad de intereses y a esta compleja difusión de poder.

En las postrimerías del gobierno de Carter, la invasión de Afganistán hizo surgir diagnósticos sombrios que afirmaban la muerte de la detente, al mismo tiempo que corrían rumores de una Tercera Guerra Mundial (G. Lagos, 81) Estas ominosas predicciones se han acentuado durante la Administración Reagan y el clima de retorno a la guerra fría ha impregnado el ambiente de las relaciones entre las dos superpotencias. La política de EE. UU, en la medida en que se encuadra en la lógica simplificada de la guerra fría, tendrá que encontrarse con los obstáculos que emanan de la nueva estructura de poder y de conflictos (G. Lagos, 81).

Es dentro de este contexto global que es posible estudiar fructíferamente las relaciones entre EE. UU. y América Latina.

\section{La respuesta a la crisis hegemónica: de la alternativa liberal de Carter a la alternativa conservadora de Reagan.}

Parece indudable que la conjunción de Vietnam -símbolo de la crisis de poder externa -y Watergate-, simbolo de la crisis de poder interna- produjo en EE. UU. una crisis de confianza. Objetivamente esta crisis fue el producto del fin de la superioridad económica y militar de EE. UU. a nivel mundial y de sus repercusiones en el sistema político interno. Subjetivamente, a nivel de las percepciones de los actores del sistema político, esta crisis fue diagnosticada preferentemente como una crisis de liderazgo que requería de un nuevo impulso, de un cambio de dirección de tal envergadura que permitiera revertir la tendencia declinante y recuperar para EE. uU. su posición de superioridad y liderazgo mundiales.

Ya en sus discursos como candidato presidencial, Garter se hacia eco del sentimiento nacional al expresar: "no pretendo poseer todas las respuestas, lo que sí poseo es un intenso sentimiento de que este país está a la deriva y que necesita de un nuevo liderazgo y una nueva dirección" (G. Lagos, 77). Un año después agregaba: " $\mathrm{He}$ comprendido que ya era tiempo de que nuestro país tomara la bandera de una causa pura y honesta, justa y digna". (G .Lagos, 77). Esta era la causa de los derechos humanos a través de la cual Car- 
ter buscaba una nueva identidad para el país, identidad disociada de la imagen imperial. (Soares y Hirst, 81).

Carter planteaba una visión del mundo de acuerdo con la cual la creciente complejidad de los asuntos mundiales no podía ser manejada por las superpotencias ni tampoco reducida a las relaciones entre ellas. En una afirmación agresiva del idealismo norteamericano redefinió el interés nacional a partir de un impulso moral en defensa de los derechos humanos, integrando esta concepción en la visión de un mundo en el cual, debido a la difusión del poder en nuevos actores emergentes que luchaban por liberarse de las antiguas dependencias coloniales y económicas, las condiciones de la influencia norteamericana estaban destinadas a cambiar. El "liderazgo sin hegemonía" era el único camino posible. La mejor mnnera de tratar los avances y maniobras soviéticas era a través de una diplomacia preventiva en que no todo exito soviético podía ser evitado a un costo razonable o constituía una amenaza para el interés norteamericano. No toda pérdida era una derrota y la división del mundo en dos campos era una fórmula artificial que generaba su propio fracaso, ya que trataba como enemigos a países o fuerzas cuyos lazos con los soviéticos eran temporales y contaba como aliados a regímenes cuyas debilidades internas o ambiciones externas podían convertirse en factores negativos para Washington y oportunidades para Moscí. Al igual que Nixon, Garter percibía un mundo de múltiples polos de poder en el cual la penetración soviética en el Tercer Mundo se estrellaría contra la barrera nacionalista. (Hoffmann, 81).

La implementación de la política de derechos humanos a nivel mundial, reveló muy pronto que su aplicación se restringía a los países considerados como no prioritarios para los intereses estratégicos de los Estados Unidos (Soares y Hirst, 81), y que dentro de esta concepción América Latina era un campo privilegiado para su realización. "La preponderancia de los $\mathrm{EE}$. UU. en la región parecía " asegurar a priori el éxito de esa política. En la medida en que " no existían amenazas fundamentales a los intereses de seguridad " de los EE. UU. en América Latina, ésta aparecía como un área se" gura para llevar a cabo las políticas con un costo relativamente "bajo". (Soares y Hirst, 81). Pero aún en la región, las vacilaciones y desaciertos en la aplicación de estas políticas pusieron en evidencia la crisis de poder de los EE. UU. en el continente. (Soares $y$ Hirst, 81).

En suma, Garter representó "una alternativa liberal a la crisis, de "la hegemonía norteamericana en el plano mundial; los fracasos de "su política terminaron por reforzar una respuesta conservadora " a esta misma crisis". (Soares y Hirst, 81), que llevó a la elección de Ronald Reagan. 
Si para Carter la forma de superar la crisis de poder norteamericana había sido la instauración de un "liderasgo sin hegemonia" en un mundo multipolar de gran complegidad, para Reagan la visión de la debilidad norteamericana debe ser contrarrestada por una afirmación directa de la hegemonía norteamericana. "En el programa de Reagan esto sign:fica reafirmar la superioridad norteamericana en los planos económico (frente a la competencia de otras economías capitalistas), militar (frente a la URSs) y de acción política internacional (en el plano del Tercer Mundo). En esta línea de reafirmación hegemónica, la imagen de la "amenaza externa", el "peligro soviético" cumple un rol en la movilización de recursos políticos". (Portales, 81).

Si para Carter el nuevo liderazgo y la nueva dirección debieran surgir de la reunión de los ciudadanos tras "la bandera de una causa pura y honesta, justa y digna", para Reagan el impulso renovador debe nacer de un nuevo patriotismo, de una nueva visión del destino manifiesto de EE. UU. que llevará al país a recuperar su supremacía perdida, a encabezar a Occidente frente a la amenaza soviética y a lograr nuevamente que EE. UU. sean el número uno en todos los campos, afirmando su liderazgo $y$ predominio en escala planetaria. La URss y sus aliados deben ser contenidos porque representan una amenaza ideológica para los valores y la seguridad de Ee. uU., sus aliados y sus amigos. Para ello es preciso el crecimiento inmediato de los gastos militares y un fortalecimiento de la economía norteamericana, verdadero motor que mueve al mundo libre. Una vez que los ex.tu. tengan una posición fuerte en el plano económico y militar, los soviéticos no tendrán otra alternativa que negociar. (Roett, 81).

En esta política de afirmación hegemónica y de contención de la amenaza soviética, América Latina pasa a tener una función clave, porque es el lugar más apropiado y ventajoso, en términos de correlación de fuerzas con Moscú para la contención de la urss. (Maira, 81). De esta manera, América Latina, al igual que en la época de Garter, se convierte en campo privilegiado para la aplicación de la politica exterior de Washington.

\section{El Nuevo Destino Manifiesto de EE. UU.}

Con Reagan pareciéramos asistir a un neo-sueño americano: un mundo regenerado por la nación portadora de un Nuevo Destino Manifiesto. Esta nación es el fruto de una experiencia única, en la cual ciudadanos libres construyeron una sociedad donde imperan la ley, el orden y la equidad. Si el mundo internacional en su totalidad no puede ordenarse conforme a esta pauta, es porque se interpone el interés de agentes de potencias que se oponen al orden libertario. La nación vive, entonces, el dilema de tener que optar 
entre el aislarse en casa ante la desilusión que le ocasiona el mundo exterior al ver incomprendidos sus valores o, por el contrario, asumir su responsabilidad moral y política en el exterior desempeñando el rol de agente justiciero, conteniendo la agresión de los enemigos de la libertad y restituyendo el imperio de la ley, el orden y equidad internacional.

Reagan estima que después de dos décadas de decadencia de la política exterior de los EE. UU. (Podhoretz, 8I), es ya hora de que la nación asuma su rol participacionista en los asuntos mundiales ejerciendo el "liderazgo" que sobre la base de su poder y experiencia histórica le corresponde.

La revitalalización del liderazgo moral y político debe darse fundado en un diagnóstico acerca de la situación de EE. UU. en el mundo contemporáneo. Reagan lo tiene: $\mathrm{EE}$. UU. y el continente americano están bajo "ataque extremo" por parte de la URss y la subversión interna por ésta alimentada (Kirkpatrick, 81; Santa Fe, 81), y esto se debe a que la política de coexistencia pacífica, primero, y de distensión, después, al único que perjudicó es a E€. UU. (Kirpatrik, 81) y en los hechos ha equivalido a una estructura de paz basada en la retirada estratégica de EE. UU. (Podhoretz, 81).

$\mathrm{La}$ propuesta ante este diagnóstico es que EE. UU. debe retomar la iniciativa en la pugna ideológica bipolar comunismo-democracia de la Doctrina Truman (significativamente Reagan se inspiró, en su Mensaje al Congreso sobre la crisis centroamericana en 1983, en el discurso de Truman al Congreso en 1947, en que se articuló la Doctrina Truman) y revalorizar el conflicto estratégico Este-Oeste, postergado durante la Administración de Carter por la pugna económico-social. Norte-Sur que en definitiva termina siempre (Podho retz, 81) con el Sur alineado al Este.

Es dentro de este contexto de revitalización de la dimensión estratégica y de defensa de la política exterior, orientada a fortalecer el área de seguridad de EE. UU. y del "mundo libre", que se revaloriza a América Latina en razón de su importancia como zona estratégica segura.

Esta reinserción del rol de América Latina en la política exterior de EE. UU. es una nueva versión de la teoría del "patio trasero"; en lo esencial: la zona es de alto interés estratégico para EE.UU. y área de influencia segura, en consecuencia, no puede permitirse la injerencia política ni ideológica de potencias extracontinentales, mucho menos la intervención militar. Por tanto, EE. UU. considera acto hostil toda acción de violación a este principio e incluso se siente en el legítimo derecho de intervenir (aún militarmente) ante actos de tal naturaleza.

Un impartante corolario de esta visión es el considerar una irresponsabilidad la indiferencia estratégica hacia la zona por parte de 
nómenos políticos nuevos (Maira, 82), valiéndose de un análisis pragmático y factualista que intenta integrar la perspectiva de conservadores ortodoxos, neoconservadores y conservadores del "establishment", logra formular una visión ideológica clara de la región. En este sentido no se puede acusar a la política exterior de Reagan de una tradicional incoherencia, asistematicidad e improvisación hacia América Latina. Lo cierto es que dentro del ciclo interésnegligencia de la política exterior de EE. UU. hacia la región, con Reagan hemos asistido a una etapa de interés dada, confirmando la teoría del ciclo, en razón de una crisis en la percepción de la seguridad estratégica de los EE. UU. y donde la región se inserta como zona de prueba de la nueva concepción estratégica de contención.

Lamentablemente, la nación portadora del nuevo Destino Manifiesto da la batalla estratégica enarbolando un ideario libertario que en términos ideológicos dice poco en una región donde el espacio de libertad es estrecho $y^{r}$ el margen de desigualdad ancho.

\section{El escenario predilecto}

Los problemas de América Central han sido el eje de la política hacia América Latina de la Administración Reagan, por cuanto esta subregión aparece como escenario más a punto para llevar a la práctica la política de contención.

Al efecto, Reagan interpreta la aparición de cualquier estallido revolucionario en Centroamérica como el resultado de la estrategia global de expansión del comunismo que impulsa la uRss y su aliada regional: Cuba; por consiguiente, el problema centroamericano se encuadraría perfectamente en el esquema de confrontación EsteOeste. Se acepta la existencia de factores internos que pueden explicar la emergencia de movimientos sociales disruptivos, pero se cree que apenas éstos emergen pasan a ser manipulados por planes internacionales del comunismo. Se cree en la "contaminación" de los fenómenos revolucionarios y de acuerdo a la "teoría del dominó" Io esencial de la política exterior de los EE. UU. debe ser impedir el reemplazo de gobiernos "amigos" (a veces no muy amigos del ideario y práctica política estadounidense) por fuerzas políticas hostiles o neutrales hacia EE. UU.

El tema de que "una lejana potencia totalitaria" está creando una seria amenaza para la seguridad de los EE. UU. se repite cada vez con mayor frecuencia en los pronunciamientos de Reagan y sus asociados. Sobre la base de este argumento es que las operaciones de los EE. UU. en América Central constituirían una respuesta defensiva a la agresión que ya están cometiendo la uRss y sus secuaces cubanos y nicaragüenses.

Durante 1983 el gobierno de Reagan demostró que cree firme- 
mente en una "relación especial" con América Central y el Caribe. Por supuesto el Presidente Reagan tiene un concepto diferente al académico acerca de la "relación especial".

Por un lado, la invasión de Grenada y la creciente presencia militar norteamericana en Centroamérica ofrece evidencias de que el gobiemo de Reagan considera a la Cuenca del Caribe como su propia esfera de influencia y está dispuesto a usar la fuerza si fuere necesario para hacer frente a la penetración de otros poderes dentro del área. Esto constituye una clara confirmación -como lo fuera la invasión soviética a Afganistán- de que las superpotencias no se sienten inclinadas a apegarse a normas internacionales cuando consideran que sus intereses estratégicos en la confrontación Este-Oeste se ven amenazados.

Por otro lado, las revelaciones sobre una participación directa de la Agencia Central de Inteligencia en actividades tales como el minado de puertos nicaragüenses y ataques a instalaciones petroleras han originado una aguda oposición en el Congreso estadounidense. Ambas Cámaras aprobaron, por abrumadora mayoría, resoluciones condenando Ias acciones de la CIA, atacándola, además, por su intento de mantener en la oscuridad al Congreso con relación a operaciones secretas. Como réplica, el gobierno de Reagan apeló al patriotismo y lanzó una contraofensiva acusando al Congreso de socavar la política exterior de EE. UU. al condenar públicamente las operaciones de la cra. (Visión, mayo 84).

La búsqueda de un amplio apoyo a la política centroamericana de la Administración Reagan en un año electoral fue el propósito de la Comisión Kissinger, que en enero de 1984 entregó su informe sobre la política hacia América Central. (G. Lagos, 84).

Para hacer frente a la crisis, la Comisión Kissinger propone más ayuda militar y más ayuda económica. El énfasis en la grave crisis económica $\mathrm{y}$ social ha sido bien acogida, aunque sus propuestas para mejorar las condiciones económicas merecen dudas, por cuanto se espera un rol decisivo de la empresa privada en una región donde no existe infraestructura material, politica ni cultural para su desarrollo nativo o por avecindamiento foráneo. Con relación a la ayuda militar, ya en febrero la Conferencia Episcopal Católica de EE. UU. protestó por los propósitos del Gobierno de Reagan de aumentar la ayuda militar al Gobierno de El Salvador, basado en el Informe Kissinger: "Aún reconociendo la dimensión internacio" nal del conflicto y aceptando la posición oficial de que un abrup" to corte de toda ayuda militar de EE. Uu. puede originar un de" sangramiento aún más caótico, urgimos una disminución gradual "del apoyo militar y reforzar los frentes políticos y diplomáticos". (Maloné, 84).

Tampoco se puede olvidar que el gobierno de Reagan está con- 
virtiendo al pais más pobre de América Central, Honduras, en un puesto de avanzada norteamericano, erizado de nuevas instalaciones militares. $Y$, mientras tanto, las autoridades militares panameñas $y$ estadounidenses continúan adelantando las conversaciones pertinentes para el mantenimiento de la Escuela de las Américas en Panamá, cuyo período vence en octubre de 1984, de acuerdo con los tratados Carter-Torrijos. La permanencia de la Escuela de las Américas, bajo otra denominación, conllevaría la garantía por parte de Panamá de permitir a EE. UU. el continuar entrenando militares extranjeros en Panamá. (Bernal, 84).

Dentro del contexto del enfrentamiento Este-Oeste y del consiguiente "Iiderazgo" del "mundo libre" lo que, al parecer, realmente importa al Presidente Reagan y sus asesores es que las crisis revolucionarias en América Central puedan ser percibidas, dentro y fuera de EE. UU. como una pérdida para este país y como una ganancia para el "comunismo internacional". En medida importante, no es el comportamiento en sí de soviéticos, cubanos o nicaragüexases lo que está en cuestión, sino la percepción que otros -el electorado norteamericano y los líderes de las naciones más disímiles del mundo- puedan tener de la "voluntad" o "firmeza" del "liderazgo" de EE. UU.

La contrapartida al predominio de la política de contención de las crisis en América Central ha sido el que la Administración Reagan no ha tenido otra política frente a América Latina. Como resultado comienza a pagar un alto precio por su abandono de las demás subregiones: a la crisis centroamericana se han agregado la descomposición del sistema interamericano -ya muy debilitadodespués de la guerra de las Malvinas y la aguda crisis financiera que encaran los países de la región.

\section{Las discolas "potencias intermedias"}

De la revisión que la Administración Reagan hizo de la política de EE. UU. hacia América Latina, Ia búsqueda de "acuerdos especiales" o. "preferentes" con las "potencias intermedias", prioritariamente Brasil y México y, en seguida Argentina y Venezuela, subsistió como una pieza fundamental de la política hacia la región.

Sin embargo, la política de Reagan hacia América Central y el Caribe, la guerra de las Malvinas y la crisis financiera han confabulado para que no sólo los "acuerdos preferentes" no prosperaran, sino que incluso el sistema interamericano se encuentre hoy cuestionado e inoperante.

Por razones históricas, de vecindad geográfica y por la proyección de su política exterior, América Gentral y el Garibe han jugado un papel especial en la política internacional mexicana, hasta 
el punto que se ha considerado que la subregión constituye actual - potencialmente una zona de influencia mexicana.

El enfoque de guerra fría que ha impregnado la política de Rea. gan ha chocado con la visión mexicana de orientación tercermundista y de apertura a los regímenes izquierdistas. Así como la pojítica exterior de Reagan está dominada por la obsesión de la "teo. ría del dominó" y la consiguiente práctica de la "contención", para México existe una obsesión paralela, que es la de impedir la "libanización" de la región (Maira, 82), es decir, su desintegración por una sucesión de guerras civiles "internacionalizadas" y prolongadas que tendrían un profundo efecto disociador en toda el área, pudiendo llegar incluso a afectar la estabilidad mexicana.

El objetivo de México en América Central y el Caribe es contribuir a la emergencia de un orden que tenga condiciones de estabilidad y viabilidad y que sea capaz de eliminar o reducir substancialmente los profundos antagonismos que desgarran a algunas naciones centroamericanas como El Salvador y Guatemala.

Las políticas exteriores de Washington y Brasilia necesariamente habian de llegar a un importante desacuerdo dadas las distintas visiones del sistema internacional que inspiran a ambas Cancillerías.

Las líneas fundamentales de acción de la política exterior brasileña tienden a la maduración de la fórmula que enunciara el Canciller Azeredo da Silveira: "el pragmatismo responsable", que implica el rechazo a todos los "alineamientos automáticos" y, por consiguiente, a todo enfoque de guerra fría (G. Lagos, 74; 80). Ante estos principios y orientaciones que se han traducido en una afirmación creciente de la autonomía brasileña en la búsqueda de un espacio mundial para su política exterior, no as de extrañar la reticencia de Brasil a la política centroamericana y caribeña de Reagan y su rechazo a cualquier intento de intervención militar en la conflictiva región.

Significativamente, pese a que los países involucrados se encontraban negociando sus respectivas deudas externas con el apoyo del Departamento del Tesoro norteamericano, en abril de 1983, los presidentes de México y Brasil firmaron una declaración oponiéndose a Ia intervención estadounidense en Centroamérica, situación que suscitó el disgusto de la Administración Reagan. (H. Muñoz, 84).

La relación Washington-Caracas ha presentado características muy peculiares que dieron posibilidades al intento de Reagan de crear un acuerdo o entendimiento especial con Venezuela. El hecho que el jefe de gobierno salvadoreño de mayor permanencia durante el período (primero, presidente de la Junta de Gobierno, hoy, Presidente de la Nación elegido en comicios) sea un democratacristiano (Napoleón Duarte), en un tiempo exiliado en Venezuela, y que cuenta con la confianza de los dirigentes de coper (Democracia Cris- 
tiana venezolana), partido de gobierno hasta 1983, llevó a Venezuela a apoyar al gobierno salvadoreño y a compartir su visión de la guerra civil. Por esta razón coyuntural, Washington encontró un inesperado aliado para su política centroamericana.

Empero, Venezuela es un país que a lo largo de sucesivos gobiernos democráticos ha venido desarrollando una política autonomista. Por consiguiente, la circunstancial coincidencia de intereses con Washington frente a la situación salvadoreña no fue impedimento para que Venezuela se incorporara en forma decidida al Grupo Contadora (Venezuela, México, Colombia, Panamá), que ha plạnteado una alternativa distinta para la crisis centroabiericana, privilegiando la vía política-diplomática y descartandıs con firmeza las "necesarias" soluciones de fuerza que acompañan todas las iniciativas del gobierno de Reagan.

Hoy es claro que los gobiernos de Venezuela y México han decidido tener voz y jugar un rol en el desenlace de los problemas centroamericanos en función de perspectivas e intereses que no coinciden necesariamente con los de la Casa Blanca y para ello han tenido la habilidad y capacidad de crear un grupo negociador (Contadora) que ha adquirido la estatura y respetabilidad suficiente como para que el gobierno de Reagan acepte a este comensal inesperado.

En cuanto a Argentina, los esfuerzos iniciales de la Administración Reagan por constituir una relación "especial" con Buenos Aires se vieron coronados por el éxito. En efecto, el gobierno militar de Argentina, en especial desde que asumió la Presidencia el general Galtieri, adoptó una actitud marcadamente anticomunista frente al conflicto centroamericano, llegando a vías de hecho con aporte de ayuda militar al gobierno de El Salvador y a medidas económicas contra Nicaragua y Cuba.

El beneplácito de la Administración Reagan por esta tan necesaria ayuda de "naciones amigas", al parecer, obnubiló por completo de la mente de los decisores de la Casa Rosada de comienzos de 1982 Ia trama y jerarquía de compromisos mundiales de sus amigos de la Casa Blanca. La decisión de invadir las Islas Malvinas con tropas argentinas puso a la Administración Reagan en la disyuntiva de optar entre un amigo "preferente" y otro más que preferente. El desenlace fue obvio.

Este lamentable episodio, junto con desmoronar abruptamente la política de acercamiento a las potencias intermedias de América Latina $y$ dejar al sistema interamericano en completa falencia, mostró el complejo entrecruzamiento de factores y la multipolaridad del escenario político mundial actual, donde una superpotencia como EE. UU. ni siquiera fue capaz de lograr un acuerdo "entre amigos" para salvar una borchornosa y lamentable confrontación béli- 
ca "entre amigos". Cabe preguntarse si en este escenario es viable una política de "liderazgo del mundo libre".

\section{Los negrocios son "particulares" y "privados"}

El interés económico, de siempre, de EE. uU. en la región se da en términos del acceso a materias primas, a mano de obra barata y a mercados de cierta magnitud. Estos temas adquirieron bajo la política de Reagan una valoración en términos de la concepción de Seguridad Nacional basada en una visión de confrontación estratégica.

De acuerdo a esta visión, América Latina no representa un centro de interés prioritario para la seguridad económica de EE. UU., por cuanto es un mercado en merma tanto para exportaciones como para inversiones, pero estratégicamente es importante dada la disponibilidad de recursos naturales de alta escasez potencial y la alta asimetría de la relación económica EE. UU-América Latina. En razón de esta asimetría el mercado norteamericano es altamente determinante para las posibilidades económicas de la región, aun cuando proporcionalmente decreció durante la década de los setenta -tendencia que de nuevo pareciera revertirse con la recesión de los dos últimos años-. Por tanto, la política exterior económica de EE. uU. hacia América Latina es, también, importante porque afecta la seguridad económica de una zona dentro del área de seguridad estratégica de EE. uU.

Conforme a esta visión, la política de Reagan se inició bajo un prisma altamente ideologizado porque, en atención al rol estratégico que este sector de la política exterior debía jugar, toda la acción en el plano económico se basó en el supuesto compromiso ideológico regional con la contención del comunismo y el estímulo a los principios clásicos del capitalismo económico como un componente más del discurso político: libre empresa, inversión privada nacional y extranjera, liberalismo económico en el comercio internacional.

Se presuponía que este plan debería operar sin acuerdos políticos internacionales en materias económicas, por cuanto son los agentes económicos privados los animadores innatos de las relaciones económicas internacionales. Las relaciones políticas intergubernamentales deberían orientarse a estimular y dejar espacio a las iniciativas de agentes económicos privados, según fuere la realidad de cada país de la región.

La ayuda económica concesional no se descarta, pero se parte de la premisa que, dado el grado de desarrollo medio de la región, no constituye ya una zona que requiera este tipo de ayuda, salvo cuando razones de seguridad estratégica o confrontación política lo aconsejen (léase Centroamérica). 
La iniciativa de la Guenca del Garibe es un caso claro, donde se muestra que, dadas razones de seguridad estratégica, se considera conveniente llegar a acuerdos políticos internacionales en materias económicas. A la vez, el plan es una muestra diáfana de la visión ideológica de la Administración Reagan acerca de materias económicas. En efecto, la iniciativa se fundamenta en tres principios acordes a la ideología económica de la administración: formación de un área de libre comercio, incentivo a la inversión privada y ayuda económica concesional para el desarrollo.

A poco andar, el plan ha encontrado dificultades que constituyen un buen muestrario de las que, en general, se dan en América Latina en relación a las premisas de la política exterior económica de la Administración Reagan. En primer lugar, se produce una contradicción entre el librecambismo y las decisiones de política exterior en la medida que esta última acentúa la confrontación y no la apertura y el compromiso político, creando un clima poco propicio para la confianza de agentes privados nativos y foráneos que supuestamente deben dinamizar el comercio y la inversión. Una segunda fuente de contradicción es el intento de multilaterización política del plan, para lo cual se invitó a participar a otros países con intereses regionales (México, Canadá), pero, a la vez, el manejo político que la Administración Reagan hace de la ayuda económica (se incorpora a EI Salvador, pero se margina a Nicaragua) le da un carácter claramente bilateral al esquema de funcionamiento del plan.

En general, da la impresión que las iniciativas de política exterior en materia económica hacia América Latina son un intento de salvataje en un dedal en medio de una mar gruesa. La retórica en política exterior económica no ha seguido a los grandes problemas económicos regionales y las iniciativas específicas, como la del $\mathrm{Ca}$ ribe, parecen de menguado efecto marginal, a más de dudoso éxito político. Las vías de solución para la región están en decisiones macroeconómicas y acerca de ellas no se conocen planteamientos oficiales.

Frente a grandes temas como la deuda externa regional, no ha habido liderazgo gubernamental y la política de la Administración Reagan ha sido dejar que opere la banca privada y esperar a que cada "cliente" negocie sus problemas financieros según sea su particular situación. ¿Hasta cuándo esperar? ¿Hasta que los grandes deudores de América Latina (¿Argentina?) creen problemas graves en la banca estadounidense $y$, entonces, decidirse a un "plan Illinois" generalizado? (En mayo de 1984 el Federal Reserve debió inyectar 7.500 millones de dólares al Continental Illinois -uno de los ocho bancos estadounidenses más grandes- ante el creciente pánico entre sus depositantes, que lo puso al borde de la quiebra, lo cual prueba que en el país del libre mercado el negocio financiero, 
cuando de grandes se trata, no es una actividad en la que "el que quiebra, quiebra").

\section{7. ¿De vuelta al "predominio"?}

La incapacidad de la Administración Reagan de resolver en términos de fuerza el desafío de Nicaragua y El Salvador, a pesar de la demostración de Grenada, la creciente politización de los problemas económicos de la región, a pesar de la política "privada" de Washington, y las difíciles relaciones con las potencias intermedias de América Latina demuestran en la práctica el nuevo horizonte multipolar que comienza a caracterizar la inserción internacional de la región. Han quedado atrás los tiempos en que las opciones políticas y el comportamiento internacional en estos países se decidía sólo en Washington.

Los países latinoamericanos han ganado grados de autonomía respecto a EE. UU. La contribución del Grupo Andino al término de la dictadura de Somoza en Nicaragua, el papel mediador y moderador que están ejerciendo los países del Grupo Contadora, la creciente autonomía de la política exterior de las "potencias intermedias" (Argentina, Brasil, México) son clara demostración de ello.

En materia de seguridad colectiva, pilar fundamental del sistema interamericano, se acrecienta la diferencia entre la perspectiva global tipo confrontación estratégica Este-Oeste de la Administración Reagan y el punto de vista regional de América Latina.

Para el Gobierno de Washington es vital disuadir cualquiera amenaza a su territorio y lo que considera su esfera de influencia, por tanto, combatirá el más mínimo intento de dar bases de apoyo operacional a fuerzas militares extrarregionales que pudieren desafiar sus intereses estratégicos. América Latina, por su parte, tiene interés en la mantención de la paz dentro de la región, la que puede ser amenazada tanto por conflictos intrarregionales como por conflictos con potencias extrarregionales. La guerra de las Malvinas demostró que esta última posibilidad no es sólo hipotética para los países de Âmérica Latina, a la vez que EE. uU., dados sus compromisos que se extienden mucho más allá de América, demostró que no siempre puede ser considerado un paraguas protector de los países latinoamericanos. La amenaza de conflictos intrarregionales tampoco ha estado ausente; además de Centroamérica, hubo una situación prebélica entre Chile y Argentina y preves estallidos entre Perú y Ecuador.

El problema principal de la política exterior de EE. UU. hacia la región durante las últimas administraciones ha sido la incapacidad de incorporar un elemento fundamental de las relaciones interamericanas de la actualidad, cual es el descenso de la hegemonía norteamericana y la consiguiente redistribución del poder. El período 
de postguerra, de hegemonía casi absoluta de EE. UU. ha terminado. Los gobiernos latinoamericanos son crecientemente autónomos y han diversificado sus relaciones económicas, militares, políticas y culturales.

El gobierno de Reagan parece decidido a negar o ignorar estos hechos. Así se explicaría que "el resultado concreto de las políticas "de Reagan en América Latina es -como apunta Abraham Lowen" thal en un sugerente artículo- una situación similar a la que pre"valecía durante la década de 1920. En esa época, EE. uv. era una "potencia dominante, pero no hegemónica, en América del Sur y "poseía influencia significativa, pero no exclusiva; las potencias " europeas tenían intereses y compromisos en Sudamérica y varios " países de la región figuraban como potencias medianas a nivel "mundial $y$, finalmente, la intervención norteamericana se limita" ba a Centroamérica y el Caribe. En suma, la política latinoame" ricana de Reagan se originaría en un temor acerca de la hegemo" nía perdida". (H. Muñoz, 84).

Bernal, Miguel A. "¿Y los Tratados Torrijos-Carter?" Revista Vision, 26 de marzo, 1984, pp. 16-17.

BouzAs, Roberto. "La politica económica del Gobierno Republicano: contenidos, obstáculos y perspectivas". Cuadernos Semestrales Estados Unidos: Perspectiva Latinoamericana. No 9, 1.er semestre 1981, pp. 110I 40 .

- "Dos años de polftica económica republicana". Revista Mensaje. Vol. XXXIr, enero-febrero 1983, No 316 , pp. $11-14$.

Comité de Santa Fe. "Las relaciones interamericanas", (Documento). Cuadernos Semestrales... op. cit., pp. $181-214$.

CONNELL-SMITH, Gordon. "The crisis in Central América: President Reagan's options". Revista The World Today. Vol. 39, No 10, october 1983, pp. 385-892.
DALlAs, Roland. "A new start in EI Salvador". Revista The World Today. Vol. 40, june 1984, pp. 223-225.

ESTÉvEZ, Jaime. "AAdonde nos arrastra la crisis económica internacional?" Revista Mensaje. Vol. xxxirI, agosto 1984, No 331, pp. 356-358.

FALK, Richard. "The menace of the new cycle of interventionary diplomacy". Journal of Peace Research. Vol. xvIr, NQ 3, 1980, p. 203.

HofmMan, Stanley, "Requiem". For eign Policy. Spring, 1981, pp. 3-5.

JofFE, Josef. "European American Relations: the enduring crisis". Foreign Affairs. Spring, 1981, p. 850.

KIRKPATRIK, Jeane. "Dictaduras y dualidad de criterios". Revista Estudios Públicos. N.os 4-5, septiembre-diciembre 1981, pp. 189-216.

- "U. S. Security in Latin America"Commentary. January 1981. En: Estudios Públicos, Santiago, N.os 4-5, 
septiembre-diciembre 1981, pp. 157185.

LAGos, Gustavo. "Brasil, la vocación mundial de un imperio nación". Revista Mensaje, agosto 1974, No 23I, pp. 331-337.

- "El impacto mundial de la ofensiva ideológica de Carter". Revista Mensaje, septiembre 1977, p. 469.

- "Las relaciones entre América Latina, Estados Unidos y Europa Occidental". Santiago, Chile, Editorial Universitaria, 1979, pp. 164-166.

- "Brasil en Africa: una polf́tica realista". Diario El Mercurio, 17 diciembre 1980, p. A-3.

- "Entre la detente y la guerra fria". Revista Estudios Internacionales, año Xrv, octubre-diciembre 1981, No 56 , pp. $485-492$.

- "E1 informe Kissinger: una operación de relaciones públicas". Revista Mensaje, vol. xxxur, julio 1984, No 330, pp. 291-293.

Matra, Luis. "América Latina, pieza clave en la política de contención de la Administración Reagan". "América Latina y la crisis de hegemonia norteamericana", Luis Maira. DESCO. Centro de Estudios y Promoción del Desarrollo, Lima, junio 1982, pp. 219-267.

- "La política latinoamericana de la Administración Reagan: del diseño armonioso a las primeras dificultades". "América Latina..., op. cit., pp. 269-323.
- "Impacto y lecciones de la crisis Centroamericana". Revista Cono Sur, FLAcso. Santiago, vol. II, No 4, noviembre-diciembre 1983, pp. 3-5.

MLAlone, James W. "Protesta por el aumento de la ayuda militar a EI Salyador". Revista Mensaje. Vol. xxxill, octubre 1984, No 333, p. 498.

MuÑoz, Heraldo. "El escenario internacional: continuidad o cambio". Revista Mensaje. Vol. xxxur, enero-febrero 1984, No 326, pp. 11-13.

PoDkoretz, Norman. "EI Peligro Presente". Cuadernos Semestrales ... op. cit., pp. 110-140.

PORTALES, Carlos. "Hacia una nueva Guerra Fria. Percepciones y realidades en la politica internacional de los $80^{\prime \prime}$. En folleto colectivo mimeografiado. Academia de Fumanismo Cristiano, 1981.

- "Seguridad y relaciones Estados Unidos-América Latina". Revista Cono Sur. Op cit., pp. 3-5.

- "Estados Unidos y los pueblos de América Latina". Revista Mensaje. Vol. xxxiII, agosto 1984, No 331, pp. 379-383.

RoETr, Riordan. "The Reagan Administration and Latin America". Annual Meeting of RIAL. Quito, Ecuador, november 1981, mimeografiado.

So Ares, María Regina; HIRst, Mónica. Estados Unidos y América: cerrando una época en descomposición. Revista Estudios Internacionales, octubrediciembre 1981, No 56, p. 535. 